\title{
Narcissus rupicola Dufour ex Schult. \& Schult. fil. (Amaryllidaceae), novedad florística para Andalucía occidental (España)
}

\section{Javier López-Tirado}

Departamento de Ciencias Integradas. Facultad de Ciencias Experimentales, Campus de El Carmen, Universidad de Huelva, 21071 (Huelva).

\section{Correspondencia}

J. López Tirado

e-mail: javier.lopez@dbasp.uhu.es

Recibido: 12 abril 2018

Aceptado: 3 octubre 2018

Publicado on-line: octubre 2018
Narcissus rupicola Dufour ex Schult. \& Schult. fil. (Amaryllidaceae), new record for western Andalusia (Spain)

Palabras clave. Corología, Amaryllidaceae, Narcissus rupicola, novedad, Córdoba.

Key words. Chorology, Amaryllidaceae, Narcissus rupicola, new record, Cordoba.
CóRDOBA. Villaviciosa de Córdoba: Riscos de Vera [30SUH3907], 660 m, 29-III-2018, J. López Tirado s.n. (COA 58549).

Narcissus rupicola Dufour ex Schult. \& Schult. fil. es un endemismo de la Península Ibérica cuya área de distribución se extiende por las provincias de Ávila, Badajoz, Burgos, Cáceres, Ciudad Real, Guadalajara, Jaén, Logroño, Madrid, Orense, Salamanca, Segovia, Soria, Toledo, Zamora y Zaragoza en España; Beira Alta, Beira Baixa, Minho y Trás-os-Montes en Portugal (Aedo,
2013), si bien sus mayores poblaciones se ubican en el Sistema Central (anthos y gbif). Tiene un comportamiento ecológico principalmente rupícola, y crece en repisas y grietas de rocas de carácter ácido (Navarro, 2009).

Recientemente, se ha recolectado un ejemplar en la provincia de Córdoba (Fig. 1), lo que supone la primera cita de la especie en Andalucía occidental (cf. Valdés, 1987).

En el momento de la recolección se han encontrado varios ejemplares en fructificación, y
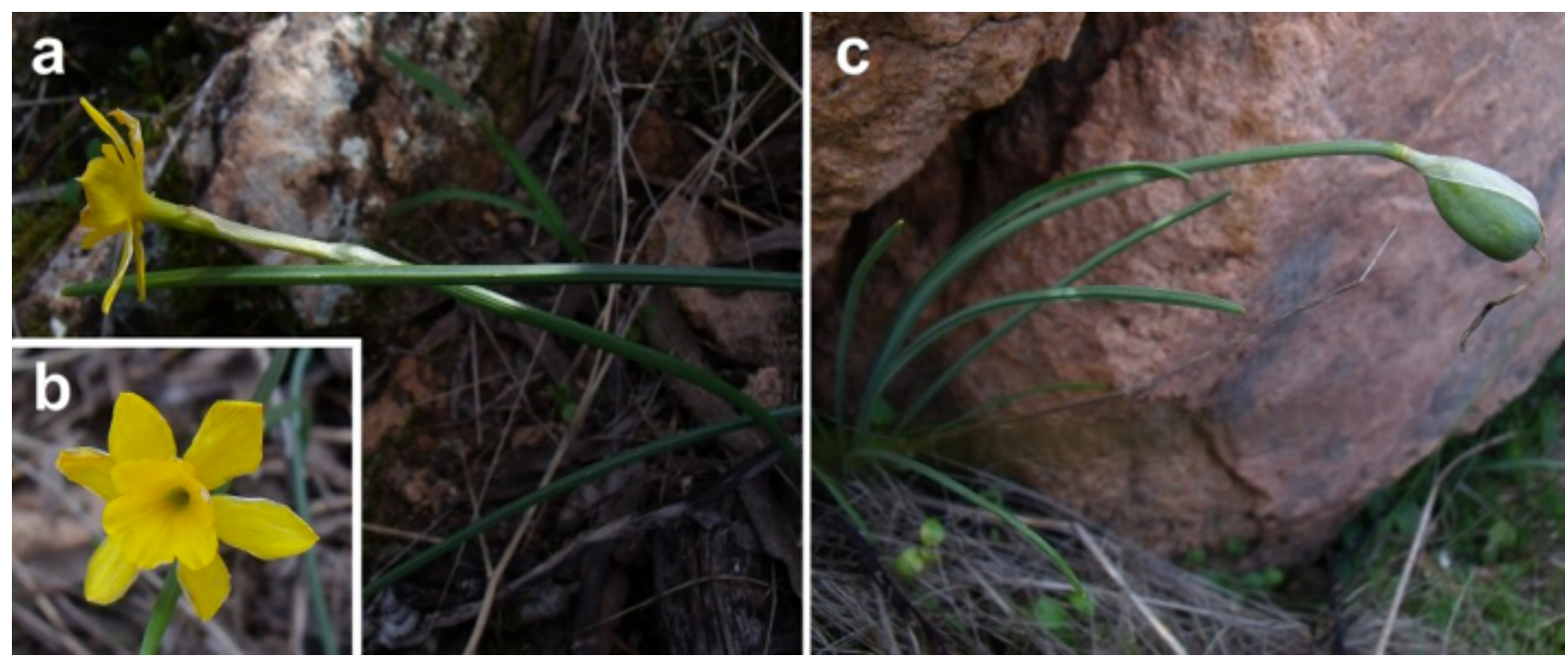

Figura 1. Vista lateral (a) y frontal (b) de N. rupicola en flor; vista lateral (c) en fructificación. Fotografías tomadas en la nueva población.

Figure 1. Lateral (a) and frontal (b) view of N. rupicola in blossom; lateral view (c) fructifying. Pictures have been taken from the new population. 
solo uno en floración. Aparecen como rupícolas, en substrato granítico, en la parte más alta del cerro muestreado. Convive con $N$. triandrus subsp. pallidulus (Graells) Rivas Goday, aunque en el momento de la exploración no se detectaron ejemplares del híbrido $N$. x rupidulus Fern.Casas \& Susanna. En las proximidades sí que coexisten $N$. triandrus subsp. pallidulus y $N$. jonquilla L., y el híbrido de ambos narcisos, $N$. x hervasii Barra \& Ureña (Barra \& Ureña, 2014). Las poblaciones más cercanas de la especie se localizan en las provincias vecinas de Jaén y Ciudad Real, concretamente en Sierra Morena (Martín-Blanco \& Carrasco, 2005; Navarro, 2009), y en Andalucía oriental es considerada especie muy rara (Navarro, 2009).

Con la presente cita se amplía la distribución de $N$. rupicola a Andalucía occidental, siendo la población cordobesa la más meridional conocida hasta el momento.

\section{Bibliografía}

Aedo, C. (2013). Narcissus L. In, S. Castroviejo et al. (eds.) Flora Iberica, XX (pp. 340-397). Madrid: Departamento de Publicaciones del CSIC.

Anthos. Sistema de información de plantas de España [http://www.anthos.es/; consultado en abril de 2018]

Barra, A. \& Ureña, F. (2014). Narcissus $\times$ hervasii Barra \& Ureña (Amaryllidaceae), una nueva especie híbrida. BV news Publicaciones Científicas 3(37): 9-11.

GBIF. Global Biodiversity Information Facility [http:// www.gbif.org/; consultado en abril de 2018]

Martín-Blanco, C.J. \& Carrasco, M.A. (2005). Catálogo de la flora vascular de la provincia de Ciudad Real. Monograf. de la AHIM, vol 1.

Navarro, F.B. (2009). Amaryllidaceae. In, G. Blanca et al. (eds.) Flora Vascular de Andalucía Oriental, 1 (pp. 169-181). Sevilla: Consejería de Medio Ambiente, Junta de Andalucía.

Valdés, B. (1987). Narcissus L. In, B. Valdés et al. (eds.) Flora Vascular de Andalucía Occidental, 3 (pp. 463474). Barcelona: Ketres Editora S.A. 